\title{
حق التعليم في ظل حالة الطوارئ
}

\section{( دراسة في اطار التشريعات الوطنية والدولية )}

\author{
م.م. مؤيد محمد عبدالقادر ، قسم العلوم السياسية، جامعة نوروز، أقليم كوردستان العراق
}

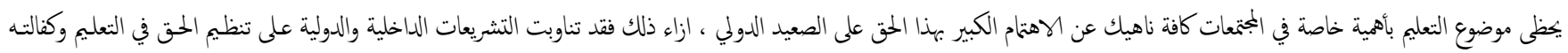

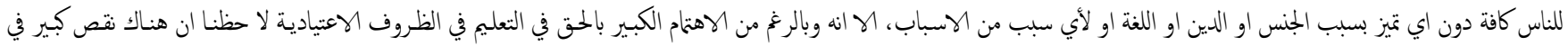

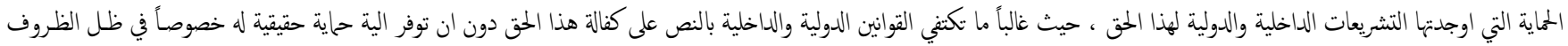

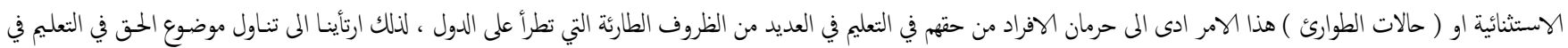

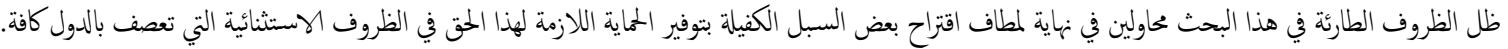
الكلمات الدالة : التعليم ,حالة الطوارئ , الحعلان العالمي لحقوق الانسان.

1

يعد الحق في التعليم من الحقوق ذات الاهمية الخاصة حيث حظي هذا الحق 3.1 منهجية الدراسة

اعتمدنا في كنابة هذا البحث على المنهج التحليلي و ذلك من خلاك تحليل النصوص الدستورية و الدولية التي تناولت بالتنظيم الحق في التعليم و ذلك بقصد بيان كيفية تعاملها مع حالات الطوارئ، فضلاً عن بيان مدى فعاليتها في ظل تلك

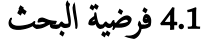

تنطلق فرضية البحث من نقطة اساسية مفادها ان الجهود الوطنية و الدولية التي تناولت الحق في التعليم بالتنظيم قاصرة عن توفير الضانات الكفيلة او التي تضمن للفرد التمتع بالحق في التعليم في ظل حالات الطوارئ. 5.1 صعوبات البحث تجسدت صعوبة البحث في قلة المصادر التي تناولت موضوع المحاية الدولية للحق في التعليم في ظل حالات الطوارئ الامر الذي اضطررنا معه الى الاستعانة بالمبادئ العامة التي عالجت هذا الموضوع بقصد توظيفها في اطار دراستنا.

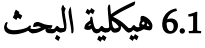

بهدف الحاطة بمفردات البحث من جوانبه كافة تم تقسيمه على مبحثين ، حيث تناولنا في المبحث الاول ماهية التعليم والظروف الطارئة وقد تم تقسيم هذا المبحث على مطلبين حيث تناولنا في المطلب الهول مفهوم التعليم ، اما المطلب الثاني فقد تناولنا فيه مفور حالة الطوارئ ، اما المبحث الثاني فقد تناولنا فيه باهتام كبير جداً على الصعيدين الداخلي و الدولي على حدٍ سواء، و اذا كان الوضع الطبيعي هو أن يتمتع كل فرد بهذا الحق دون اي عائق الح أن هناك ظروف معينة قد تحول دون الاتنفاع منه كان تمر على الدولة احداث طارئة أو استثنائية تعرقل ولو بشكل مؤقت عملية الانتفاع او التمتع بها الحتق

\section{1}

لموضوع البحث اهمية كيرة وهذه الاهمية نابعة عن كنه (البحث) يتناول الاليات التي اوجدها المجتمع الداخلي و الدولي على حذٍ سواء لضان تمتع الأفراد بجق التعليم في حالات الطوارئ التي لا نكاد تخلو منها اي مجتمع من الجنمعات، ان كانت على فترات متقطعة، فالبحث في مستوى المماية التي اوجدها الجمتعان محل الدراسة له اهمية خاصة بغية تقيم هذا المستوى واقتراح السبل الملائمة لتطويره.

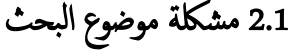

تدور مشكلة موضوع البحث حول ايجاد اجوبة مناسبة للتساؤلات التالية: ما القصود بالحق بالتعليم و ما هي مشتملات هذا الحق.

ما المقصود بمبدأ تكافٔ الفرص العلمية و ما هي اركان هذا المبداً. ما هي الاليات التي اوجدها المجتع الداخلي و الدولي لضان حق التعليم في

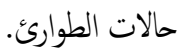
ما المقصود بحالة الطوارئ و كيف تؤثر هذه الحالة على الحق في التعليم. 


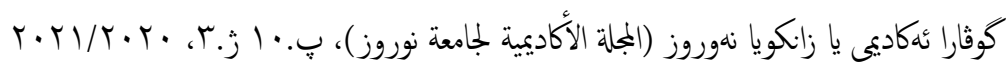

و حسب اعثقادنا أن هذا التعريف يفتقد الى الصياغة الدقيقة فهو اقرب الى مفهوم العملية التعليمة منه الى التعليم، و بالتالي فأن هذا التعريف يصلح للتعبير عن العملية التعلميمة ولكنه لا يصلح للتعبير عن التعليم بحد ذاته . و تم تعريف الحت في التعليم ايضا بأنه ( حق كل الانسان في أن يتلقى القدر الذي لئي

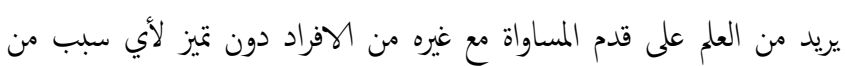
الاسباب، كما يكون له الحق في تعليم وتلقين غيره من العلم و المعرفة و نقل آرائه

$$
\text { للأخرين و التعبير عنها بحرية و بدون قيود) (5). }
$$

و هناك من عرف الحق في التعليم على انه ذلك الحق الاصيل ذو الطابع الاجتاعي و الذي يتطلب من الدولة القيام بسلوك ايجابي لتمكين اصحابه من التمتع به، و ذلك من خلال توفير المؤسسات و المراكز التعليمة المناسبة و الكوادر اللازمة لإمكانية التمتع بكافة مشتملات هذا الحق بما يتضمنه من مجموعة من

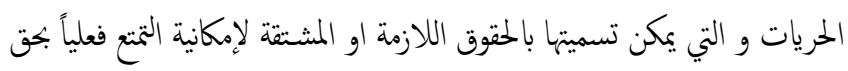
النعليم بالمفهوم الواسع و دون ذلك ييقى حق التعليم مصطلحاً اجوف و فارغاً من اي معنى او مضمون حقيقي (6). ايضاً تم تعريف الحق في التعليم بأنه ( المكنة الممنوحة للأفراد بتلقي العلوم و المعارف و المعتقدات التي تتناسب مع قدراتهم و تتاشى مع رغباتهم، مع ضرورة توفير الامكانيات و السبل المناسبة للوصول المى ذلك و تحقيقه سواء من قبل الدولة بأنشاء المؤسسات التعلمية العامة المناسبة و الكافية وفقاً لقدتها و امكانياتها المتاحة او من خلال الزام الآباء بارسال ابنائهم الى المدارس و المراكز النعليمة (7). هذا ومن الجدير بالذكر الى ان الحق في التعليم له جملة من الخصائص يككن اجلهالها

بما يلي : n أ. انه حق الحديث النشآة من الناحية الدستورية : من حيث الإقرار بحق

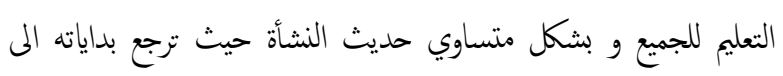

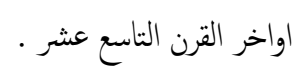

ب. انه حق أساس: حيث لا تخلو دساتير الدول كافة من الإشارة الى هذا

$$
\text { الحق سواء اتم ذلك بشكل صرئ ام ضمني. }
$$

ج. انه حق اجتماعي اطرافه الفرد و الدولة و الجماعة و بالتالي لا يكن الحديث عن هذا الحت او التمتع به الا في اطار الجماعة ، وليس هناك مجال للحديث عن هذا الحق في حالة العزلة بالنسبة للأفراد .

\section{2. المبحث الاول: ماهية التعليم والظروف الطارثة}

ان نشوب النزاعات المسلحة او حدوث الكوارث الطبيعة، وانتشار الاوبئة كلها غالباً ما تكون سباً في اعلان حالة الطوارئ، و التي تلقي بضلالها على مختلف مناحي الحياة و من ضنها بطبيعية الحال (الناحية التعلمية) و بالنظر لما يؤدي اليه اعلان حالة الطوارئ من انتطاع في العملية النعلمية، و تدهورها، نرى ان الضرورة تقضي البحث في ماهية التعليم في ظل حالة الطوارئ، ولأن الامر و لأغراض التوضيح يقتضي منا التطرق الى كلا المفردتين (التعليم، وحالة الطوارئ) كل على حده ارتأينا المى تقسيم هذا المبحث على مطلبين و كما يلي :

\section{2 المطلب الاول: مفوم التعليم}

ان البحث في مفهوم التعليم يتضضي منا التطرق الى تعريف التعليم اولاً ومن ثم بيان مشتملاته ، عليه ومن اجل الاحاطة بمفردات هذا المطلب من جوانبه كافة

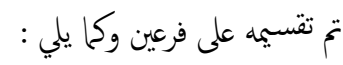

\subsection{2 الفرع الاول: تعريف التعليم}

ثمة جملة من التعاريف التي وضعت للتعليم من جانب الفقهاء، حيث عرفه البعض بأنه ((النشاط الذي مهدف الى تطوير المعرفة والقيم و الفهم و الادراك الذي يمتاج اليه الفرد في كل مناحي الحياة اضافة الى المعرفة و المهارات ذات العلاقة

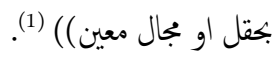
كما تم تعريف التعليم بأنه (( هو ايصال المعلم العلم و المعرفة الى اذهان التلاميذ بطريقة قويمة، و هي طريقة اقتصادية توفر لكل من المعلم و المتعلم الوقت و الجهد في سبيل الحصول على العلم و المعرفة)) (2). و عرف الحق في التعليم ايضاً بأنه (( قدرة الفرد على أن يتلقى قدراً من المعرفة و يخصل على قسط من التعليم بحرية تامة، و أن يختار العلم الذي يريد أن يتعلمه و ينتقي من يشاء من المعلمين الذين يتلقى منهم العلم، و ان تهنيأ للإنسان فرصة التعلم و ذلك على قدم المساواة مع غيره من ابناء جنسه فلا يفضل عليه صاحب

$$
\text { جاه او ثروة بسبب وجاهته او ثروته) (3). }
$$
و هناك من يذهب في تعريفه للتعليم الى القول: انها عملية تضم بمحوعة من الاستراتيجيات و الاساليب التي يتم من خلالها تنمية المعلومات و المهارات و الاتجاهات عند الفرد او بجموعة من الافراد سواء اكان ذلك بشكل مقصود او غير مقصود بواسطة الفرد نقسه او غيره . (4). 


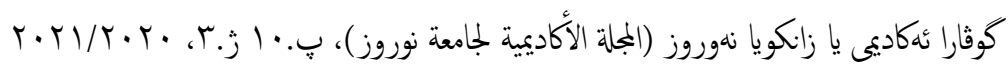

العدالة او النكافؤ في فرص العمل بعد التخرج .

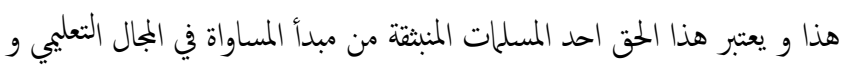
يتضمن عدم الاعتراف بأي نوع من انواع التنظيم التعليمي الذي يكرس التميز بين

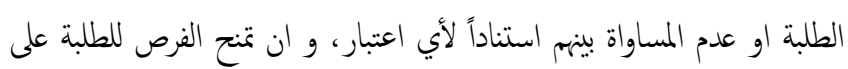
قدم المساواة في تلقي التعليم و توعيته فضلاً عن تلتي المساعدات التعلمية سواء

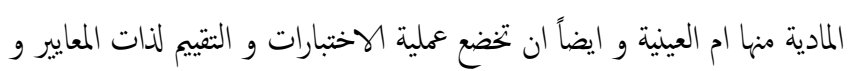
ان تتسم هذه المعايير بالموضوعية و الشفافية و العدالة بحيث تكون هذه المعايير

قادرة على ابراز الفروقات الفردية بين الطلبة في مجال التحصيل العلمي ـ (12).

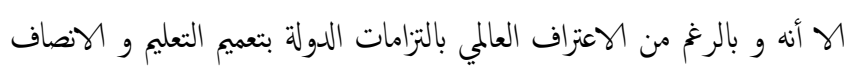
في الوصول اليه على كافة المستويات (الابندائي، الثانوي والعالي) و بجمبع السبل المناسبة فأن التعليم لايزال غير مناح و ليس هناك تكافئ للفرص في التعليم في العديد من البلدان و خصوصاً في الدول النامية .

ثالثأ: الحق في اختيار نوعية التعلم :

كقاعدة عامة يعترف للأفراد بالحق في اختيار نوعية التعليم الح أنه و لاعتبارات تتعلق بواجبات الدولة المترتبة عليها في المجال التعليم اضافة الى تامين العمل لمواطنها فأن المشرع الدستوري عادة ما يسمح للمشرع العادي بوضع بعض القيود

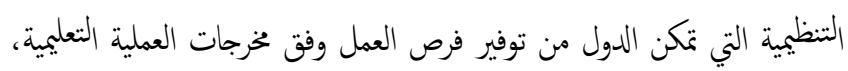
كأن تقوم مثلاً برض بعض الشروط و المتطلبات الاكثر شدة في بعض انواع التعليم كدراسة الطب او الهندسة على سبيل المثال، لكن من دون الهخلال بمبدأ المساواة بين المتنافسين على المقاعد المخصصة لمثل هذه التخصصات و ذلك بغية تمكين الدولة من الوفاء بالتزاماتها من خلال توجيه امكانياتها المادية . (14). رابعا : الحق في تأسيس المراكز التعليمية الخاصة :

ان مشاركة القطاع الخاص في مجال التعليم تعتبر من المسائل التي تم الاعتراف بها، حيث ثمة اعتزافا عاما بحت الكافة في انشاء المدارس والمراكز التعلمية الخاصة ، على ان يكون ذلك تحت رقابة واشراف الدولة وموافتتها المسبقة ووفقا للشروط التنظيمة المنظمة لذلك. هذا ومما لاشك فيه ان المدارس والمراكز التعلمية الخاصة تمارس دورا تكميلياً مع المدارس والمراكز العامة ، لذلك فان المنظومة التي تخضع لهاكل منها متشابها من حيث الطاقة الاستيعابية والكوادر الكاديمية والمناج التي يتم اعتادها وذلك يتم

تحت رقابة واشراف السلطة العامة المختصة (15).
د. انه حق إيجابي بالنسبة للدولة : و هذا يعني انه يجب على الدولة ان تتخذ

$$
\text { سلوكا ايجابياً من اجل تمكين الافراد من التمتع به (8). }
$$

2.1.2 الفرع الثاني: مشتملات الحق في التعليم

ينثثق عن الحق في التعليم جملة من الحقوق الاخرى التي تعتبر بمثابة مكملات للحق في التعليم، و لعل اهم تلك الحقوق المنبثقة عن الحق في النعليم بما يلي : اولاً: حقوق الآباء في مجال الثعليم لأبناهُه: يعتبر هذا الحق من الحقوق اللازمة لحق الآباء بالتعليم، حيث يمنح الآباء حقاً في

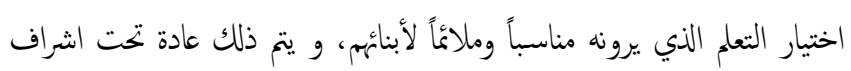

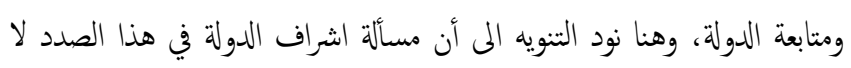
تصل الى حد الزام الدولة الاباء بإرسال ابنائهم الى مدارس معينة لغرض التعليم و انما تتوقف مسئولية الدولة عند حدود التأكد من قيام الاباء بإرسال ابنائه لتلقي التعليم الذي يتناسب مع قدراتهم الفردية و توجهاتهم (9).

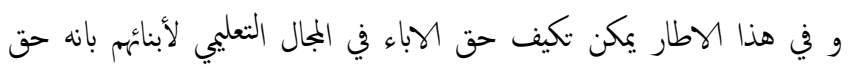
اساسي فردي و مشتق لكنه يصبح حقاً اساسياً جاعياً عند الحديث عن منظومة الحت بالنسبة للآباء جميعاً على المستوى الوظيفي ولكن يجب التأكيد هنا أن هذا الحق الممنوح للإباء تجاه تعليم ابنائه لا يمنح الآباء الحق في المشاركة المباشرة في العملية التعلمية و إن كان هناك أثر غير مباشر من خلال عضوية مجالس اولياء الامور في المدارس (10).

ثانياً: الحق في تكافث الفرص في تلقي التعليم: يتمثل حق نكافُٔ الفرص في تلتي التعليم في صورة تهيئة فرص التعليم للجميع على لى اساس من المساواة بين مختلف افراد الجمتع، وهذا يعني أنه انه يتوجب على لئل المؤسسات التربوية من مدارس و جامعات ان تستوعب جميع الراغبين بمثابعة دراستهم دون اعتبارات عرفية او دنية او طائنية او جغرافية او لأي اعتبار

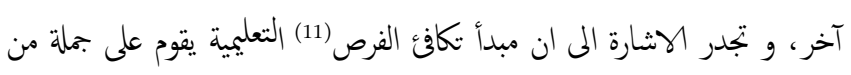

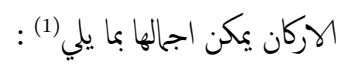
النكفؤ في القبول و الالتحقق .

التكفؤ في ظروف التعليم الداخلية او ما يعبر عنها بعدالة المعاملة . التكفؤ في الظروف الاجتاعية و الاقتصادية في الجمتع و يقصد به أن يكون هناك تكففُ او تقارب بين الافراد في الفرص الاقتصادية و الاجتاعية لمم في الحدود التي لا يسمح بضياع فرص التعليم على احد . 


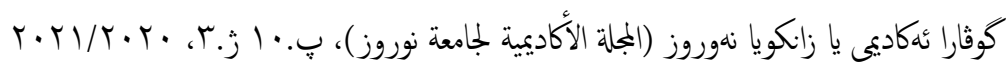

في اطار قانون الطوارئ ان تتخذ تدابير استثنائية تأخذ قوة التشريع بعد عرضها

على البرلمان والتصديق عليها و ذلك في سبيل موابحة هذه الظروف)). (20) و بعد ان أوردنا بعض التعاريف لحالة الطوارئ يتضح لنا من ما تقدم ان المقصود هذه الحالة هي انها(( عبارة عن حالة يتم الاعلان عنها بشكل مؤقت بسبب ظرف معين يسود البلاد ويجب أن تكون هذه حالة ( حلاة الطوارئ) منظمه بشكل قانوني أو دستوري كما انها نكون لفتزة مؤقته ويتجلى الهدف الأساسي

$$
\text { من الهعلان عنها في حايه المصاح الوطنية للدولة)). }
$$

وبعد هذا العرض الموجز لتعاريف حالة الطوارئ نود التنويه المى ان حالة طوارئ

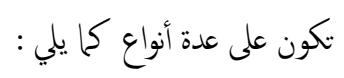

حالة الطوارئ الحقيقة: و هي التي يتم الإعلان عنها في حالة الحرب. حالة الطوارئ الداخلية: و هي التي يتم الإعلان عنها داخل الدولة و قد

$$
\text { تكون بالنسبة للإقليم معين أو محدد و قد تشمل عموم البلاد. }
$$

حالة الطوارئ الخارجية: و هي التي تعلن خارج اقليم الدولة و غالباً ما يكون ذلك اثناء الحرب و الغزو ، و يتم اعلان حالة الطوارئ الخارجية عادة

$$
\text { في المستعرات و الدول ناقصة السيادة الخاضعة لماية دول اخرى . }
$$

\subsection{2 الفرع الثاني: التنظيم الدستوري حالة الطوارئ}

تجدر الإشارة الى أن حالة الطوارئ قد تم تنظيهها قانونياً و ذلك من خلال الدساتير فضلاً عن القوانين الخاصة بذلك كما تم تنظيم حالة الطوارئ بموجب القانون الدولي و عليه سنشير في هذا الفرع الى التظيم الداخلي لحلة الطوارئ

$$
\text { فضلاً عن الاشارة الى التنظيم الدولي لها. (21) }
$$

\section{اولآ: التنيم الداخلي لحالة الطوارئ :}

على الصعيد الداخلي تم تنظيم حالة الطوارئ بموجب الدساتير فضلاً عن القوانين الخاصة وعليه سنشير في هذا الصدد الى كلاً منها على حده في العراق والبلانان

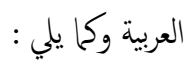

أ. التظيم الدستوري لحالة الطوارئ في العراق: الملاحظ على قانون إدارة الدولة العراقية للمرحلة الانتقالية انه لم يشير الى حالة الطوارئ، في حين تطرق الدستور العراقي الدائم لسنة (ب0. ب) الى حالة الطوارئ، حيث نصت الفقرة (تاسعاً) من المادة (61) على: يختص مجلس النواب ( أ-

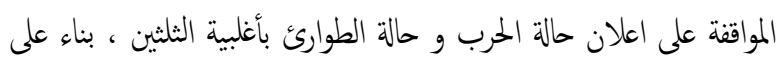

$$
\text { طلب مشترك من رئس الجمهورية و رئس مجلس الوزراء). }
$$

2.2 مطلب الثاني: مفهوم حالة الطوارئ

بعد ان تطرقنا في المطلب الاول الى تعريف التعليم ومشتملاته سنشير في هذا المطلب الى منهوم حالة الطوارئ و ذلك من خلال التطرق الى التعريف فضلا عن بيان التنظيم القانوني لها (حالة الطوارئ) و ذذلك في فرعين مستقلين و كما

\subsection{2 الفرع الاول: تعريف حالة الطوارئ}

ثمة جملة من التعارف التي وردت لحالة الطوارئ ونخن في سياق التعريف سنشير اولاً المى معنى الكلمة (طوارئ) في اللغة قبل التطرف الى المعنى الفقهي لها ـ.

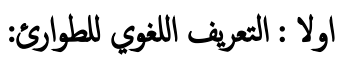

ان اصل كلمة ((طوارئ))هي من (طرأ) معناها في اللغة حدوث الشيء بشكل مفاجئ و غير متوقع يقال فطرأ على القوم ، يطراً ، اي اتاهم من مكان بعيد، و ويطلق على الغرباء (الاطراء) و هم الذين يأتون من مكان بعيد، و يقول البعض ان كلمة (طوارئ) هي جمع طارئة و معناها راهبة(16)

ثانياً : التعريف الفقهي لحالة الطوارئ : على الصعيد الفقهي هناك جملة من التعريفات ،حيث عرفها البعض بانها (( تدبير استثنائي بهدف الى حاية البلاد من هوم عسكري و شيك ، و ذلك عن طريق نظام بوليسي خاص من خلال سلطات الضبط وقد يمتد ليطال البلاد كلها او

$$
\text { يقتصر على جزء منها () (17). }
$$

و هناك من عرف حالة الطوارئ بأنها ( نظام قانوني يتقرر بمتضى قوانين دستورية عاجلة لمماية المصاح الوطنية و لا يلجأ اليه الا بصفة الاستثنائية مؤقتة لموابهة الظروف الطارئة التي تصرح عنها الادارة الحكومية الشرعية و ينتهي باتههاء مسوغاته (18) مونها كما تم تعريف حالة الطوارئ بالقول ((حالة الطوارئ نظام استثنائي، مبرر بفكرة الخطر المحدق بالكيان الوطني، يسوغ اتخاذ تدابير قانونية خصصة لماية البلاد، كلاً او جزءٌ منها ضد الاخطار الناجمة عن عدوان مسلح داخلي او خارجي وهذا النظام يككن التوصل الى اقامته بنقل السلطات المدنية الى السلطات العسكرية)) كما جرى تعريف حالة الطوارئ على انها ((الظروف الطارئة التي حدثت داخل أو خارج البلاد و تؤثر على نظام الدولة و لا تستطع السطات الممنوحة لسطات الضبط الإداري بموجب التشريعات السارية من موابهـة هذه الظروف وتستطع 


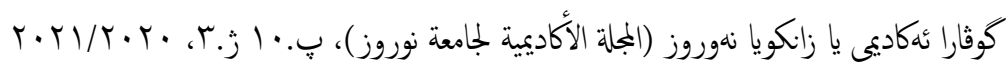

نصت هذه المادة على (( لرئيس الجمهورية إذا قام خطر حال و جسيم مهدد الوحدة الوطنية أو سلامة الوطن أو يعوق مؤسسات الدولة عن اداء دورها الدستوري ان يتخذ الإجراءات السريعة لموابجة هذا الخطر بعد أخذ رأي رئس مجلس الوزراء و رئس مجلس الشعب و الشورى و يوجه بيانا الى الشعب و يجري استقنتاء على ما اتخذه من إجراءات خلال ستين يوماً من التخاذها ولا يجوز حل مجلسي الشعب والشورى في اثناء ممارسة هذه السلطات)(23) (23) كما ان المادة (1 +1) من الدستور ذاته خولت رئس المجهورية صلاحية اصدار أو اتخاذ قرارات لها قوة القانون على ان يتم ذلك عند الضرورة و في الاحوال الاستثنائية و بناءً على تفويض من مجلس الشعب بأغلبية ثلثي اعضائه . و في الجزائر فقد تم النص على حالة الطوارئ و بشكل صريح في المادة (91) من التعديل الدستور لعالم (1997) ) حيث نصت هذه المادة على (( يقرر رئيس الجمهورية إذا دعت الضرورة الملحة ، حالة الطوارئ أو الحصار لمدة معنية بعد اجتماع المجلس الاعلى للأمن و استشارة رئيس المجلس الشعبي الوطني و رئيس مجلس الأمة و الوزير الأول و رئيس

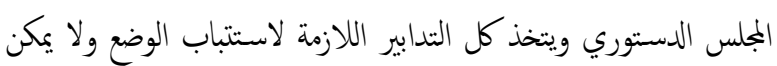
تجديد حالة الطوارئ أو الحصار الا بعد موافقه البرلمان ....). كما ان المادة (rو) من ذات الدستور قضب بأن حالة الطوارئ و حالة

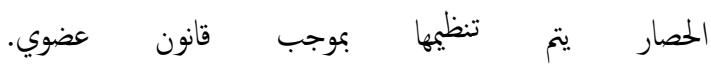
ويستخلص من هذا النص الاخير ان المشرع الجزائري قد اخذ بأسلوب التنظيم السابق لحالة الطوارئ بموجب قانون عضوي ، و يتماز هذا الاسلوب عادة بوجود قانون لحالة الطوارئ سابق على وجود حالة الطوارئ و يمكن من موابهتها فور حدوثها عن طريقة الإعلان و تطبيق

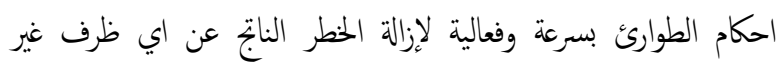
اعتيادي (24).

\section{ثانيأ: التنظيم الدولي لحالة الضرورة :}

اهتم الجمتمع الدولي بتنظيم حالة الطوارئ في الظروف الاستثنائية التي قدتمر بها الدول واصبغ عليها الصفة القانونية و الدستورية من خلال اعترافه بها بالرغز من
الواضح على ما تقدم أن الدستور العراقي الدائم لسنة (0. ㄷ) قد اعطى الحق في اعلان حالة الطوارئ لكل من (رئس الجمهورية و رئيس مجلس الوزراء، و هو بذلك لم يجعل هذا الاختصاص بيد واحدة من الرئاسات و إنما جعلها بيد رئاستين، وهي نقطة اييابية وفق رأينا للحيلولة دون استغلال هذه النقطة واساءة استعلالها. ونبقى في العراق و تحديدا على مستوى القوانين الخاصة حيث نجد ان امر الدفاع عن السلامة الوطنية العراقي قد تناول بالتنيم حالة الطوارئ حيث بينت المادة الاولى منُ الجهة التي لها الحق في اعلان حالة الطوارئ بنصها على( لرئيس الوزراء بعد موافقة هيئة الرئاسة بالجماع اعلان حالة الطوارئ في اية منطقة في العراق ، عند تعرض الشعب العراقي لخطر حال جسيم هبدد الأفراد في حياتهم و ناشئ من حملة مستمرة للعنف من اي عدد من كن الأشخاص لمنع تشكيل حكومة واسعه التمثيل في العراق أو تعطيل المشاركة السياسة السلمية لكل العراقيين أو أي غرض اخر ). (22) كما بينت المادة الثانية آلية اعلان حالة الطوارئ بنصها على (( تعلن حالة الطوارئ بأمر يتضمن بيان الحالة التي اعلنت حالة الطوارئ بسبها و تحديد المنطقة التي تشملها و تحديد بدأ سريان حالة الطوارئ و مدتها على أن لا تمتد حالة الطوارئ اكثر من (•7) يوماً و تنتهي بعد زوال الخطر او الظرف الذي استدعى قياهـا إها اقل و يجوز تمديد حالة الطوارئ بصورة دورية كل ثلاثين يوماً ببيان تحريري من رئيس الوزراء وهيئة الرئاسة إذا

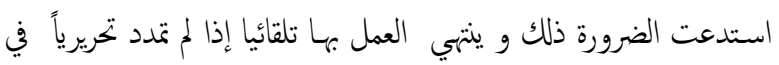
نهاية أية قترة تمديد)( ب. التنظيم القانوني لحالة الطوارئ في العربية : على الصعيد العربي ثمة جملة من الدساتير التي تناولت بالتنظيم حالة الطوارئ ، فني مصر على سبيل المثال ثمة حرص كير من قبل واضعي الدساتير المصرية على تنظيم حالة الضرورة

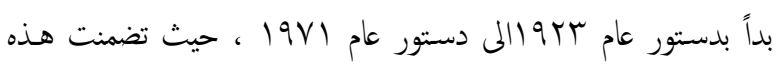

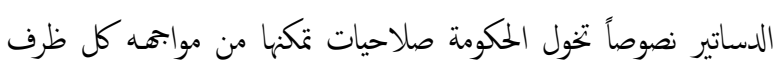

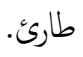
فالمادة (Vع) من الدستور المصري لسنة ا9VI ترخص لرئيس المجهورية اتخاذ الإجراءات اللازمة لمواجمة أي خطر هـدد الوحدة الوطنية أو سلامة الوطن أو يعوق مؤسسات الدولة عن اداء دورها الدستوري، حيث 


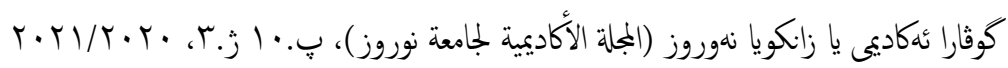
كوها تشكل خروجاً على مبدأ المشروعية عليه سنشير في هذا الصدد المى بعض و المواثيق الدولية، و من ثخ سنطرق الى اليات كفالة التمع بالمق في التعليم في حال حدوث ظروف طارئة او استثنائية و ذلك في مطلبين مستقلين و كما يلي: النصوص الدولية التي تناولت بالتنظيم حالة الطوارئ (25) .

\section{3 المطلب الأول: التنظيم القانوني للحق في التعلم} سنشير في هذا المطلب المى الحق في التعليم و تنظمه القانوني على الصعيدين الداخلي و الدولي و ذلك في فرعين مستقلين و كما يلي: 1.1.3 الفع الأول: التنظيم الدولي للحق في التعليم كفلت الاتفاقيات و الإعلانات الدولية سواء العالمية منها او الوقليمة للمواطن الحق في التعليم ، فعلى الصعيد العالمي نص الإعلان العالمي لحقوق الانسان لعام 19ع1 على ما يلي: أ. لكل شخص الحق في التعليم و يجب ان يكون التعلم في مراحله الأولى و الأساسية على الاقل بالمجان و ان يكون التعليم الاولي الزامياً.... ب. يجب ان تهدف التربية المى انماء شخصية الانسان انماءً كملا و الى تعزيز احترام الانسان و الحريات الأساسية و تنمية التفاهم و التسامح و الصداقة

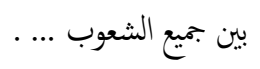
ج. للآباء على سبيل الأولوية حق اختيار نوع التعليم الذي يعطى لأولاده)) (29)

كما نص اعلان حقوق الطفل الصادر عن الجمعية العامة للأم المتحدة في · r تشرين الثاني لعام 1909 على (للطفل الحق في تلقي التعليم الذي يجب ان يكون مجانياً و الزامياً.. ) (30). وقد سار على النهج ذاته العهد الدولي الخاص بالحتوق الاقتصادية و الاجتاعية و

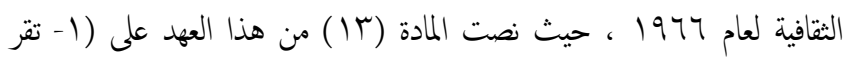
الدول الأطراف في هذا العهد بجق كل فرد في التربية و التعليم و هي مثنقه على وجوب توجيه التربية و التعلم الى الانماء الكلمل للشخصية الانسانية و الحس له بكرامتها و المى توطيد احتزام حقوق الانسان و حرياته الأساسية...). إضافة المى ما تقدم فقد ذكر الحق في التعلم في اتفاقية حقوق الطفل لعام 1919

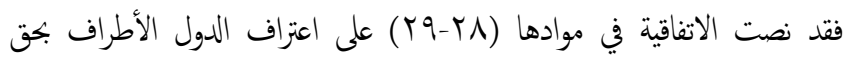
الطفل في التعليم و جعل التعليم الزامياً و مثاحاً بجاناً للجميع. اما على الصعيد الإقليم ، فقد كانت الاتفاقيات و الإعلانات الإقلمية الخاصة بحقوق الانسان حريصة هي الأخرى على ضمان و كفالة الحق في التعليم للمواطن، فقد نصت المادة (7 (Y) لعام 1979 من الاتفاقية الامريكية لحقوق الانسان على
أ. العهد الدولي الخاص بالحقوق المدنية والسياسية لعام (1977 ) : حيث جاء في العهد الدولي الخاص بالحقوق المدينة و السياسية و قدر تعلق الأمر بحالة الطوارئ ما نصه (( في حالات الطوارئ الاستثنائية التي تهدد حياة الامة والمعلن عن قياهما رسمياً يجوز للدول الاطراف في هذا العهد ان تتخذ في اضيق الحدود التي يتطلها الوضع تدابير لا تتقيد بالالتزامات المترتبة عليها بمتضى القانون الدولي و عدم انطوائها على تميز يكون مبرره

$$
\text { الوحيد هو العرق او اللون)( (26). }
$$

ب. الاتفاقية الاوربية لحقوق الإنسان لعام (1900): لم تذكر هذه الاتفاقية حالة الطوارئ بشكل صريخ و لكنها بينت الشروط الموضوعية لقيام هذه حالة حيث جاء فيها (( في حالة الحرب او الخطر العام الذي مهدد حياة آلامه يجوز لكل طرف سام متعقد ان يتخذ تدابير تخالف الالتزامات المنصوص عليها في هذا الميثاق في أضيق الحدود التي يتطلها الوضع و بشرط ان لا تتناقض هذه التدابير مع بقية الالتزامات المنبثقة عن القانون

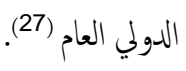
الاتفاقية الامريكية لحقوق الإنسان لعام (1979): لقد بينت الاتفاقية الامريكية لحقوق الإنسان حالة الطوارئ بشكل اكثر صراحه ووضوح حيث نصت عليها و بيت شروطها الموضوعية حيث جاء فيها (( لا يكن للادولة الطرف في أوقات الحرب او الخطر العام او سواها من الحالات الطارئة التي تهدد استقلال الدولة او امنها ان تتخذ اجراءات تحد من التزاماتها بموجب الاتفاقية الحالية و لكن فقط بالقدر وخلال المدة التي

$$
\text { تقتيها ضرورات الوضع الطارئ....) (28) }
$$

\section{3. المبحث الثاني: التظيم القانوني للحق في التعليم وكفالته في ظل الظروف \\ الطارئة}

يعتبر الحق في التعليم من اهم الحقوق التي حرصت المواثيق الدولية و الدساتير الداخلية على تنظمه ، ال ان ان الغالب الاعم من النصوص القانونية التي عالجت موضوع الحق في التعليم عالجته في ظل الظروف العادية ، لذلك ومع إمكانة حدوث ظروف طارئة او استثنائية قد تعرقل التمتع بها الحتق ، ارتأينا في هذا المبحث الإشارة أولاً الى الحق في التعلم في ظل التشريعات الداخلية و الاتفاقات 


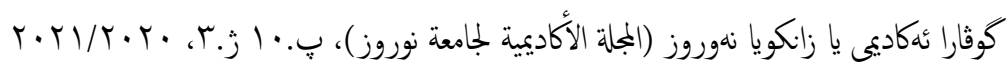

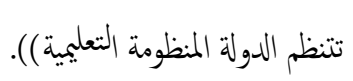

و مما تجدر الإثارة المى انه ثمة العديد من الدساتير الغربية التي نصت على الحق في

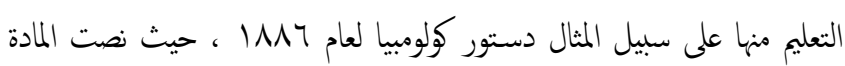

$$
\text { (1) منه على ((تضمن الدولة التعليم )). }
$$

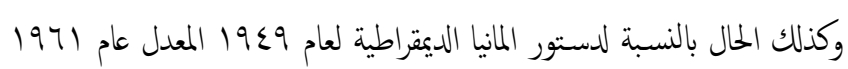
حيث نصت المادة (^^r) منه على (( التعليم الزاي حتى سن الثامنة عشر أي

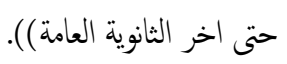

المى جانب ما تقدم ثمة دساتير أخرى نصت على الحق في التعليم منها المادة (09) من دستور المجر لعام 1941 المعدل لعام عV19 19 ، والمادة (عـ) من دستور يوغسلافيا لعام ب7 197 و غيرها من الدساتير الأخرى.

2.3 المطلب الثاني: حاية الحق التعليم في ظل الظروف الطارئة

سبق وان بينا التنظيم القانوني للحق في التعليم على الصعيدين الدولي و الداخلي و اتضح لنا ان القانون الدولي و الداخلي قد ضمن للمواطن الحق في التعليم بموجب نصوص صريحة واردة في الاتفاقيات و الإعلانات الدولية فضلاً عن التنظيم

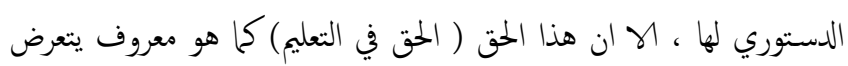
التهديد في حالات الطوارئ الامر الذي يتطلب عناية و تأميناً خاصين بهذا الحق

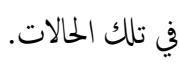

ابتداءً لابد من التنويه الى ان جحم العناية الواجبة بالحق في التعليم في الحلالات الطارئة لم يلقى ذلك المستوى المطلوب من العناية من لدن المجتع الدولي حيث ان

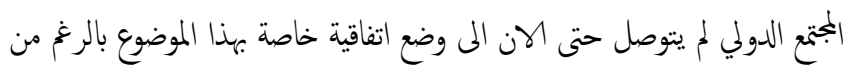

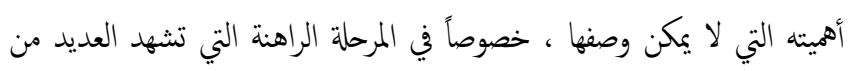
الظروف الاستثنائية او الطارئة و التي تأثر و بشكل مبانشر على الحق في التعليم. عموما ولما كان الامر كذلك فأننا مضطرون الى استغلال النصوص القانونية ذات الصلة بالحق بالتعليم في ظل الظروف الاستثنائية من الاتفاقيات و الإعلانات العامة و التي تطرقت بشكل مباشر او غير مباشر المى الحق في التعليم . حيث نصت المادة (Yr) من اتفاقية حقوق الطفل على ضرورة ان تسهر الدول على حصول الطفل الذي يطلب وضع اللاجئ على المماية و المساعدة و المماية الإنسانية المناسبتين ، فضلاً عن تتعه بجميع الحقوق الواردة في الاتفاقية ، وهذا يشمل دون شك الالتزام بتوفير الوصول الى التعليم بأسرع وقت و بشكل كامل فضلاً عن الاندماج السريع في نظام التعليم العادي.
تعهد الدول الأطراف بأن تتخذ داخلياً و من خلال التعاون الدولي كل الإجراءات اللازمة بقصد التوصل الى التحقيق الكلمل للحقوق المتضمنة في المعايير الاقتصادية و الاجتاعية و التبوية و العلمية و الثقافية المبينة في ميثاق منظمه الدول الامريكة. و هذا ما نصت عليه أيضا المادة (عا) من ميثاق الحقوق الأساسية للاتحاد الاوربي لعام (.... (Y) حيث نصت على لكل انسان الحق في التعليم و الحصول على التدريب المهني المستمر. يشمل هذا الحق إمكانية تلقي تعلم الزامي بالمجان. تحظى حرية انشاء مؤسسات تعليمية بالاحترام الواجب للمبادئ الديموقراطية و حق الإباء في ضان ان التعلم و الندريب لأطفالمم يتقق مع اعتقاده الديني و الفلسفي و التربوي وفقاً للقوانين العلمية التي تحكى ممارسة هذه

$$
\text { الحرية و هذا الحق). }
$$

2.1.3 الفوع الثاني: التنظيم القانوني الداخلي للحق في التعليم على غرار المواثيق و الاتفاقيات و الإعلانات الدولية عملت الدساتير الداخلية ايضاً على ضان حق المواطن في التعليم فالدستور العراقي لعام2005 وصف التعليم بأنه عامل أساسي لتقدم الجمتع و هو حق تكفله الدولة للمواطن ، كما قرر الدستور الزامية التعليم في المرحلة الابتدائية ومجانته في كافة المراحل ، كما الزم الدستور العراقي لعام ه . ب الدولة بالعمل على محو الامية ، فضلاً تشجيع الدولة للبحث العلمي للأغراض السلمة و بما يخدم الإنسانية و لم يغفل الدستور مسألة التعليم الاهلي حيث شملها بالتنظيم على ان يتم ذلك بقانون (31).

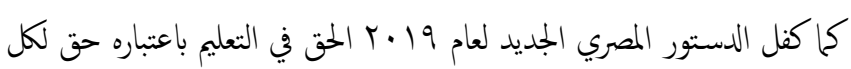
مواطن كما أقر الدستور بالزامية التعلم وبجانته بمراحله الخختلفة في مؤسسات الدولة النعلمية وفقًا للقانون (32). وكان الدستور المصري لعام 19V1 قد نص هو الاخر على الحق في التعليم حيث نصت المادة (·r) منه على ((التعليم في مؤسسات الدولة التعليمة مجاني في مراحله المختلفة)). كما ضمن الدستور الجزائري لعام 1997 الحق في التعليم حيث نصت المادة (بrه) منه على ما يلي: التق في التعليم مضمون. 


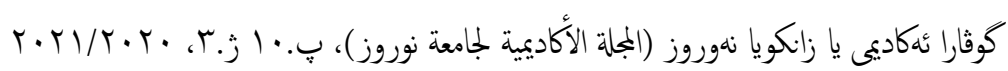

تبين لنا ان اغلب الاتفاقيات والاعلانات الدولية ذات الصلة بحقوق الانسان وكذلك الدساتير الداخلية قد تناولت بالتنظيم الحق في التعليم في ظل الظروف العادية وعدم وجود نصوص او اتفاقيات تعالج موضوع الحق في التعليم في ظل الظروف الاستثنئية او الطارئة وهو نقص كان من

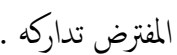

تبين لنا قصور الجهود الدولية عن ضمان الحق في التعليم في ظل الظروف الطارئة لان الغالب الوع من تللك الجهود قد جاء في اطار اعلانات واتفاقيات تعالج موضوع الحق في الظروف العادية وهي غير ملزمة للدول من غير الاطراف . م.

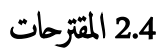

على الصعيد الداخلي ندعو المشرع الدستوري الى ضرورة معالجة الحق في التعليم بشكل مباشر ونتصد هنا الحق في التعليم في ظل الظروف الطارئ ذلك من خلال التطرق الى هذا الحق من خلال نصوص صريحة وعدم الكتفاء بالإشارة الى الحق في التعليم في ظل الظروف العادية . على الصعيد الدولي ندعو الجمتع الدولي الى ضرورة اقرار اتفاقية خاصة بالحق في التعليم في ظل الظروف الطارئة لان وجود مثل هذه الاتفاقية يعتبر ذات اهمية خاصة لضان الحت في التعليم في ظل تاك الظروف ضرورة قيام الجنمع الدولي والداخلي ضانات وبرامج استباقية تعمل على ضان الحق في التعليم في ظل الظروف الطارئة وذلك من خلال اتخاذ الاجراءات التي تكفل الانتفاع من الحق في التعليم اياً كانت الظروف .

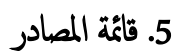

1.5

1. د. ابراهيم قلاتي ،قاموس الهدى ، دار الهدى ، الجزائر، 1997.

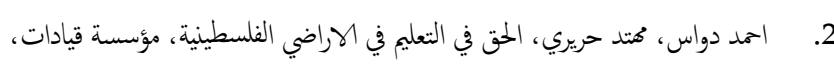

فلسطين، 2009.

3. اسراء حسين ثامر ، الاستثار الماص في التعليم العالي ، العراق حالة دراسية ، بدون

دار نشر ، 2016

4. د. ثروت بدوي، النظم السياسية دار النهة العربية، القاهرة، 1975.

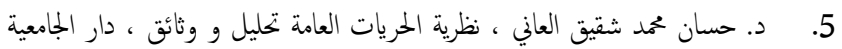

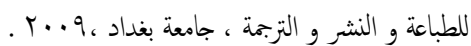

6. مد حسن دخيل , الحريان العامة في الظروف الاستثنائية , منشورات الحلبي

الحقوقية , بيروت, 2009.
كما الزمت اتفاقية حقوق الطفل الدول بضرورة اتخاذ جميع التدابير اللازمة و المناسبة لتشجيع التأهيل البدني و النفسي لضحايا النزاع المسلح و إعادة ادماجمم في المجتع ضمن جملة أمور أخرى(33). وحسب الاتفاقية الخاصة بوضع اللاجئين ينبني ان يعامل الأطفال اللاجئين معاملة الرعاية فيا يخص التعليم الابتدائي ، و معاملة لا تقل عن معاملة الأجانب فيما يتعلقة بالتعليم غير الابتدائي (34). وعلى صعيد اخر فقد اكد البروتوكل الثاني الملحق باتفاقية جنيف لسنة I9VV ، على الحق في التعليم حيث نصت (الفقرة ،3) من المادة (4) منه على وجوب توفير الرعاية والمساعدة اللازمة للأطفال والحق في تلقي التعليم . وتعتبر المادة (ᄉ) من نظام روما الأساس للمحكمة الجنائية الدولية ذات أهمية خاصة اذ تبين ان جميع الاعتداءات التي تستهدف المنشأة الخاصة بالتعليم تعد جرائم حرب و بالتالي فأها تخضع لاختصاص المحكة القضائي. وعلى صعيد اخر ادانة قرار مجلس الامن الدولي ذي الرقز (ابr| ) لعام

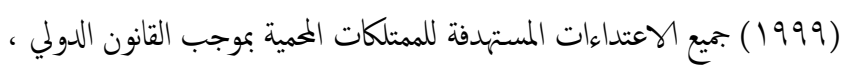
بما في ذلك المدارس و ناشد جميع الأطراف المعينة يوضع حد لهذه الممارسات.

\section{4.}

في ختام هذا البحث توصلنا الى جملة من الاستنتاجات والمقترحات سوف ندربحا

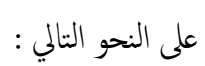

\section{4}

يعد الحق في التعليم من الحقوق المهمة التي حظيت باهتمام كبير جداً على الصعيد الدولي والداخلي على حد سواء وقد تجسدت هذا الاهتام بالنصوص الدستورية والدولية التي تناولت هذا الحت بالتنظيم حيث خصصت دساتير دول العالم والاتفاقيات والمواثيق الدولية ذات الصلة بحقوق الانسان نصوصاً مستقلة لهذا الحق وهذا ان دل على شيء انما يدل على اهية هذا الحق في تقدم المجتمعات وتطورها . ثمة عدة تعاريف وردت للحق في التعليم وايضاً لحالة الطوارئ وهي تعاريف موجودة في مختلف المؤلفات التي تناولت هذه المواضيع بالتنظيم لا اننا لاحظنا عدم وجود تعريف دقيق للحق في التعليم في ظل حالة الطوارئ وهذا يشكل نقص كان من المفترض تداركه . 


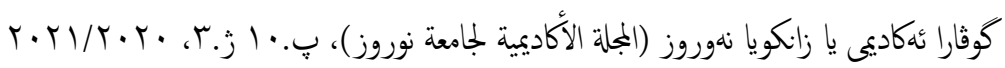

$$
\text { 6. }
$$

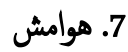

(1 ) احمد دواس، مهند حريري، الحق في التعليم في الاراضي

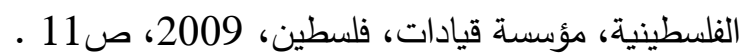

محمد علي السمان، التوجه في تعليم اللغة العربية، دار المعارف، القاهرة، 1983، صع صل 12 ـ

(3 ) د. ثروت بدوي، النظم السياسية ، دار النهضة العربية،

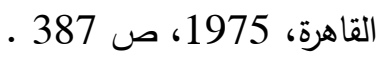

(4 ) د. محمد السيد علي ، موسوعة المصطلحات التربوية ،

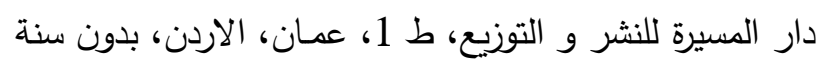

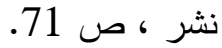

(5 ) ينظر ، د. علي محمد صالح الرياس و علي عليان

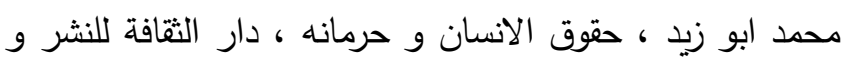

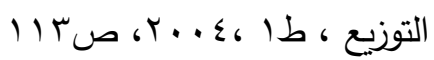

(6 ) فراس نعيم جاسم، حق التعليم في العراق بين الحماية و الانتهاك وفق احكام القانون الدولي لحقوق الانسان، مجلة دراسات تربوية، العدد ل 41، كانون الثاني، 2018، ص 288

(7 ) عيد احمد الحسبان، حق التعليم في النظم الدستورية المعاصرة، دراسة تحليلية مقارنة ، مجلة دراسات لعلوم التربية و القانون، الجامعة الأردنية، العدد (1) المجلد (39)، 2012، دعانه ، دراسله .365

(8 ) ينظر أيضا ، د. حسان محمد شقيق العاني ، نظرية

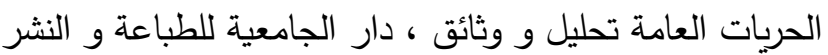
و الترجمة ، جامعة بغداد ، 9 . . Y ، ص VY V. عيد احمد الحسبان، مصدر سابق، ص 366 .

د. علي محمد صالح الرياس، علي عليان محمد ابو

$$
\text { زيد، مصدر سابق، ص عل مصل } 111 \text {. }
$$

(3) يعرف تكافئ الفرص في اطار التعليم على انه (( توفير الفرص العلمية لكل فرد مع ضرورة تتويعها و إيجاد الأجواء

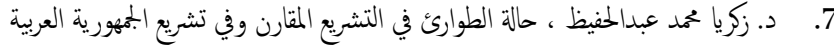
المتحدة ، منشأة المعارف ، الاسكندرية ، 1966.

8.

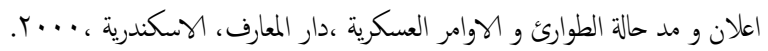

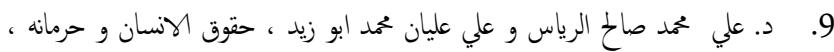

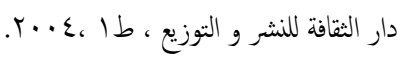

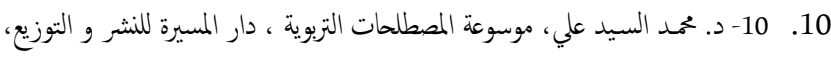
ط 1، عمان، الاردن، بدون دار نشر.

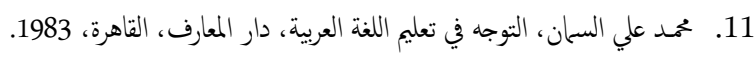

2.5

1. اسلاء امد خلف حسن ، بجانية التعليم الجامعي وملاقته بتكفئ الفرص التعليمة في

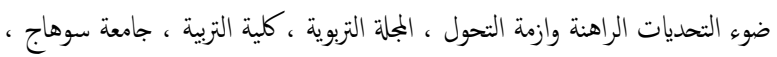
العدد (59) 2019. 2. عيد اهمد الحسبان، حق التعليم في تنظيم الدستورية المعاصرة، دراسة تحليلية مقارنة ،

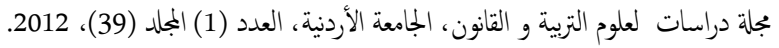

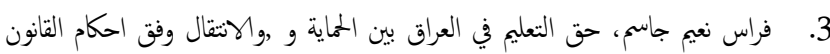
الدولي لحقوق الانسان، محلية دراسات تربوية، العدد ل 41، كانون الثاني، 2018.

3.5 1- مولودي حلول ، حاية الحتوق و الحريات اثناء حالة الطوارئ في النظام الدستوري

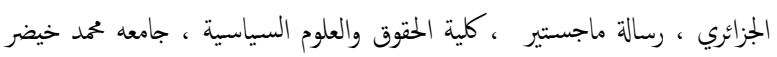

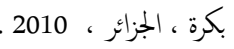

\section{5 الاتفاقيات والاعلانات والوثاثق الدولية}

$$
\begin{aligned}
& \text { 1. } \\
& \text { 2. }
\end{aligned}
$$
12. 12- وثيقة الجمعية العامة للأم المتحدة (AIHRCI17129) 18 APRIL

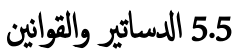
1. - دستور العراق الدائم لسنة 2005. 2.

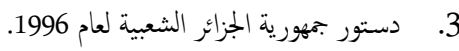

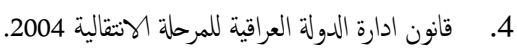

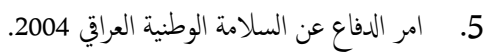


(20 ) نقلاً عن ، مولودي حلول ، حماية الحقوق و الحريات اثثاء حالة الطوارئ في النظام الدستوري الجزائري ، مولي ، رسالة

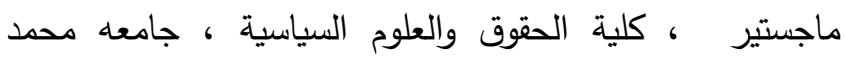
خيضر بكرة ، الجزائر ، 2010 ، صله 9 ، و

(23 ) محمد حسن دخيل ، الحريات العامة في الظروف

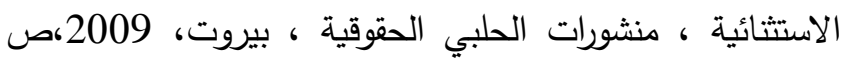

(24 ) دستور الجمهورية الجزائرية الثعبية ،منشور في الجريدة الرسمية رقم 76،المؤرخ في 8 ديسمبر 1996.

$$
\begin{aligned}
& \text { الفقرة (1) من المادة (ع) من العهد . } \\
& \text { المادة (10) من الاتفاقية. } \\
& \text { المادة (rV) من الاتفاقية. }
\end{aligned}
$$

(29 ) ينظر المادة (Y7) من الاعلان العالمي لحقوق الانسان

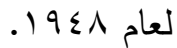
(30 ) ينظر المبدأ السابع من اعلان حقوق الطفل لعام 1909 (31 ) ينظر المادة (؟ץ) من دستور العراق الدائم لسنة . $(r .0)$

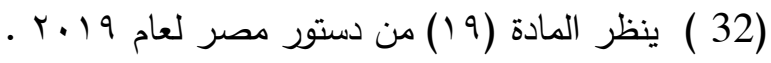

(33 ) ينظر المادة (94) من اتفاقية حقوق الطفل لعام 919 (34 ) المادة (r (Y) من الاتفاقية الخاصة يوضع اللاجئين.
الملائمة و الأسباب الدافعة داخل المؤسسة التعليمية و التي تمكن كل فرد من الاستفادة من هذه الفرص المتكافئة في تتمية

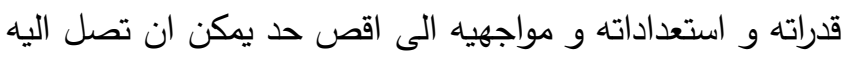

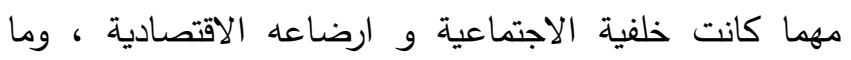

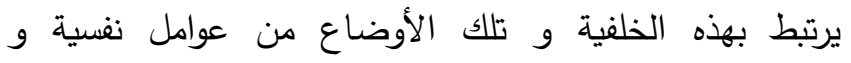
أكاديمية)) ينظر د. اسماء احمد خلف حسن ، مجانية التعليم الجامعي وعلاقته بتكافئ الفرص التعليمية في ضوء التحديات الراهنة وازمة التحول ، المجلة التربوية ، كلية التربية ، جامعة

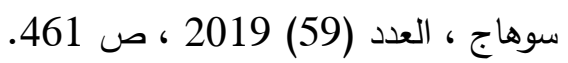
عيد احمد الحسبان، مصدر سابق، ص 367 ، 367 .

ينظر وثثية الجمعية العامة للأمم المتحدة . 2011، APRIL 18 (AlHRCI17129) عيد احمد الحسبان، مصدر سابق، ص 367 .

تجد الاثـارة الى انه قدتم افتتاح العديد من الجامعات الاهلية الخاصـة في العراق حيث بلغ عدد هذه الجامعات لغاية عام 2014 ، ( 45 ) جامعة موزعة على مختلف انحاء العراق

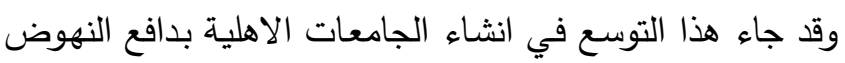

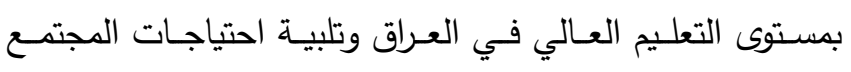

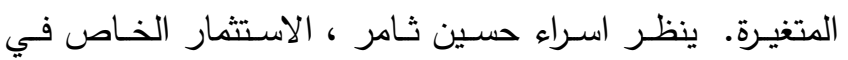
التعليم العالي ، العراق حالة دراسية ، بدون دار نشر ، 2016 ، 2016

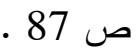
(16 ) د. ابراهيم قلاتي ،قاموس الهدى ، دار الهدى ، الجزائر . $2 \Gamma \cdot 0$. 199V (17 ) د. عبدالحميد الثواربي ، شريف جاد الله ، شائبة عدم

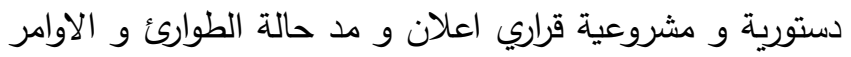

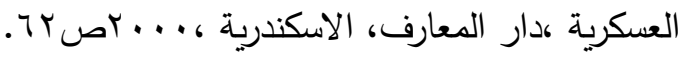

(1)د. زكريا محمد عبدالحفيظ ، حالة الطوارئ في التشريع المقارن وفي تشريع الجمهورية العربية المتحدة ، منشأة المعارف

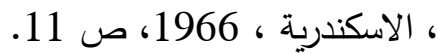
(2) د. زكريا محمد عبدالحفيظ ، المصدر نفسه ، الهن ، ص 13. 